\title{
ANAP

\section{O CULTO À FRUGALIDADE E A PRODUÇÃO ARTIFICIAL DA ESCASSEZ}

Daniela de Souza Onça

\section{Ricardo Augusto Felicio}

RESUMO: Neste artigo, localizamos a fonte do culto à frugalidade, presente em diversas alas do movimento ambientalista, na crise estrutural do capitalismo contemporâneo. Este sistema, que não consegue evitar a produção da escassez para a humanidade, formula hoje ideologias de conformismo a esta escassez, revestidas pelo ideal de preservação ambiental, em que o cultivo de hábitos frugais é apresentado como necessário a uma maior harmonia entre o homem e a natureza. Verifica-se, pois, que o culto à frugalidade representa uma racionalização ideológica capitalista para criar uma cultura de permanente escassez, acatada e desejada pela humanidade em nome do imperativo ambiental, e que a faz desconsiderar questões muito mais graves e urgentes.

Palavras-chave: Ambientalismo. Capitalismo. Ideologia.

\section{DA SOCIEDADE DA AFLUÊNCIA À SOCIEDADE DA ESCASSEZ}

Marx caracterizou a natureza imanente do capitalismo como a "contradição viva", pois cada tendência principal desse sistema só se faz inteligível se for levada plenamente em conta a contratendência específica à qual aquela está objetivamente ligada. Cada tendência possui sua lógica imanente própria, de acordo com a qual se desdobra através 
da história e, por isso, circunscreve objetivamente os limites do desenvolvimento do capitalismo global. Tal contradição se dá mesmo quando, no relacionamento entre tendência e contratendência, um dos lados necessariamente predomina, de acordo com as circunstâncias sociais, históricas e espaciais prevalecentes. Como o sistema se caracteriza pela prevalência da lei do desenvolvimento desigual, cada tendência pode se manifestar de maneira muito diversa nas várias partes do mundo, dependendo do nível de desenvolvimento dos capitais nacionais e da posição de domínio ou subordinação no interior da estrutura do capitalismo global. Assim, é possível que um dos lados objetivamente interligados predomine em um país, região ou camada social, afirmando-se como o lado dominante do complexo dialético em foco, através da trajetória global do sistema capitalista, ao passo que o outro lado prevalecerá em um local diferente. Por isso cada tendência pode apresentar grandes variações, ou mesmo inversões completas, entre uma fase e outra da história capitalista global (MÉSZÁROS, 2002, p. 653-654). No nosso caso, paralela à conhecida tendência da taxa de uso decrescente e da produção do desperdício, esta preponderante no mundo atual segundo Mészáros, e amplamente denunciada pelos movimentos ambientalistas, verifica-se também a contratendência do culto à frugalidade e da produção artificial da escassez, que, argumentaremos, é a tendência dominante de nosso tempo (e que tem a pretensão de se estender por pelo menos metade do próximo século, fomentando mais guerras, motivadas por causa de falta de água, alimentos, entre outros). Veremos agora como a ideologia ambientalista trabalha em prol dessa contratendência.

O relatório State of the World 2010 do Worldwatch Institute aborda a questão do consumismo. Logo no início, ele adverte que o padrão de consumo insustentável do ocidente faz-se presente "num número crescente de culturas de consumo no mundo" e começa hoje a ser disseminado "para milhões de pessoas dos países em desenvolvimento" (WORLDWATCH INSTITUTE, 2010, p. 3), numa clara referência à insustentabilidade da extensão dos benefícios da sociedade industrial aos chamados países emergentes. Engraçado como quando o padrão insustentável de consumo típico das nações ocidentais ricas era restrito a elas isso nunca representou um problema para 
o meio ambiente... É somente quando o consumo de combustíveis fósseis dos 1 bilhão e 300 milhões de chineses, a produção de softwares dos 1 bilhão e 100 milhões de indianos e a safra de grãos dos 200 milhões de brasileiros ameaçam superar suas correspondentes norte-americanas é que emergem as preocupações ambientais...

O relatório prossegue afirmando que, conforme aumenta a renda familiar, as pessoas gastam mais em bens de consumo, como alimentos mais processados, casas maiores, televisores, automóveis, computadores e viagens aéreas. Com o aumento do consumo, aumentam também a prospecção de petróleo, a mineração, o corte de árvores e o cultivo de terras. A exploração desses recursos para manter níveis crescentes de consumo impõe uma igualmente crescente pressão sobre os sistemas terrestres, perturbando dramaticamente os sistemas ecológicos de que a humanidade e incontáveis espécies dependem. Assim sendo, "evitar o colapso da civilização humana requer nada menos do que uma completa transformação dos padrões culturais dominantes", de uma cultura de consumismo para uma de sustentabilidade, que provoque danos mínimos ao meio ambiente (WORLDWATCH INSTITUTE, 2010, p. 3-4).

O relatório não é suficientemente insano de se esquecer do detalhe de que são as populações de países ricos que mais consomem os recursos naturais; no entanto, é interessante notar que citam como exemplo de impactos relacionados a um padrão de vida crescente a população indiana. Em níveis de renda de $\$ 2.500$ per capita por ano em paridade de poder de compra (PPC), muitas famílias têm acesso à iluminação básica e um ventilador. Quando a renda se eleva para $\$ 5.000$, cresce o acesso a água quente e o consumo de televisores torna-se padrão. Em rendas de $\$ 8.000$, a maioria das pessoas dispõe de uma gama de bens de consumo, como máquinas de lavar, aparelhos de DVD, utensílios de cozinha e computadores. Conforme a renda sobe ainda mais, tornam-se comuns o uso de ar-condicionado e viagens aéreas. Os $1 \%$ mais ricos da Índia, cerca de 10 milhões de pessoas, com renda superior a $\$ 24.500$ por ano, são responsáveis pela emissão de mais de 5 toneladas anuais de dióxido de carbono, o que, embora seja apenas $20 \%$ das emissões per capita norte-americanas, ainda corresponde ao dobro do alegado limite de emissões necessárias para limitar o alegado aumento da temperatura 
da Terra em $2^{\circ} \mathrm{C}$. Até mesmo os 151 milhões de indianos com renda acima de $\$ 6.500$ vivem acima desse limite de emissões, ao passo que os 156 milhões com renda de $\$ 5.000$ estão se aproximando desse limite, com 2,2 toneladas por pessoa. Conclui-se daí que mesmo em níveis de renda considerados medianos ou de subsistência, as pessoas já consomem em níveis insustentáveis; e hoje mais de um terço da população global vive acima do limite (WORLDWATCH INSTITUTE, 2010, p. 6-7).

\begin{abstract}
Desse modo, torna-se claro que enquanto a mudança tecnológica e a estabilização populacional serão essenciais na criação de sociedades sustentáveis, ambos não serão bem-sucedidos sem mudanças consideráveis nos padrões de consumo, inclusive a redução e mesmo a eliminação do uso de certos bens, como carros e aviões, que se tornaram parte integrante da vida para muitos hoje. Hábitos firmemente estabelecidos - de onde as pessoas moram ao que elas comem - necessitarão todos ser alterados e em muitos casos simplificados ou minimizados (WORLDWATCH INSTITUTE, 2010, p. 7. Grifo nosso).
\end{abstract}

O crescimento econômico ilimitado não só é impossível como é até indesejável, pois ele não guarda relação direta com o nosso bem-estar (e podemos mesmo dizer que, além de um certo ponto, a relação se torna inversa). O economista Kenneth Boulding sugere que o produto nacional bruto seja considerado uma medida de custo nacional bruto e que as pessoas devotem suas vidas à sua minimização - ou seja, o crescimento zero apregoado por muitos ambientalistas (WORLDWATCH INSTITUTE, 2010, p. 86-87). "O que é realmente necessário é proporcionar vidas satisfatórias com menos atividade econômica, matérias-primas, energia e trabalho necessários". Evidências empíricas sugerem que um retorno da população norte-americana aos níveis de consumo per capita da década de 1970 não deixariam as pessoas em pior situação; ao contrário, elas viveriam melhor, pois disporiam de mais tempo e recursos para investir em bens públicos de não-consumo produzidos pelo capital natural e social (WORLDWATCH INSTITUTE, 2010, p. 86).

As discussões sobre a sustentabilidade ambiental raramente abordam o uso do tempo. Estudos demonstram que quanto maior o tempo devotado ao trabalho, maior é o impacto ambiental de uma sociedade; do mesmo modo, quando se diminuem as horas de trabalho, a pegada ecológica fica menor. Isso acontece por vários motivos: primeiro, 
longas jornadas de trabalho são canalizadas para mais produção e mais consumo, redundando em maior degradação ambiental; segundo, gasta-se muita energia no transporte de casa para o trabalho e vice-versa; terceiro, as pessoas que trabalham muito tendem a praticar estilos de vida mais intensivos em recursos - suas viagens são mais "carbônicas", suas refeições fora de casa são mais rotineiras, suas casas são maiores e gastam mais energia, e sua restrição de tempo limita a prática de atividades de baixo impacto e que demandam gasto de tempo, como a jardinagem e projetos do tipo faça-você-mesmo. Longas jornadas de trabalho são estressantes, minam o funcionamento da família e os contatos sociais e provocam doenças emocionais. Quem trabalha demais tem maior propensão à depressão e ao estresse e cuida menos de si mesmo; dorme menos, o que desgasta a saúde; e não consegue se engajar em outras atividades que melhorariam seu bem-estar. Finalmente, a renda adicional proporcionada pelo sobretrabalho não gera tantos benefícios quanto se acredita. Se é verdade que mais renda produz um grandioso impacto positivo sobre famílias pobres, o mesmo não se pode dizer de uma família de classe média, que experimentará benefícios limitados em comparação com o nível de aumento da renda. Concluímos então que sociedades mais aceleradas tendem a apresentar pegadas ecológicas maiores e terríveis impactos ao bem-estar individual e social. A transição para uma cultura e uma economia sustentáveis envolverá, pois, uma adaptação a novos horários e ritmos temporais. A cultura de longas horas de trabalho e ocupações excessivas deverá ser substituída por padrões mais sustentáveis de uso do tempo. Enquanto haverá ajustes de custos, um ritmo de vida mais lento e humano trará benefícios à família, à comunidade e ao bem-estar individual. Uma pesquisa do Center for a New American Dream, datada de 2004, apontou que $85 \%$ das pessoas que optaram por um downgrade no estilo de vida estavam felizes com a mudança, mesmo reduzindo sua renda (WORLDWATCH INSTITUTE, 2010, p. 91-94).

\section{A NECESSIDADE DE REESTRUTURAÇÃO DO CAPITALISMO}




\section{ANAP Brasil}

ISSN 1904-3240 V. 3, n. 3

Concordamos com Bernardo quando este diz que a ecologia constitui "um projeto global e ideologicamente articulado de remodelação das condições gerais de produção e de reestruturação interna do capitalismo em novos mecanismos de funcionamento econômico e social" (BERNARDO, 1979, p. 153). O objetivo da ideologia ambientalista consiste, pois, em descobrir uma maneira de superar uma crise de produtividade, contudo mantendo-se no quadro das relações sociais básicas que definem o capitalismo. É por esse motivo que não coloca os verdadeiros problemas de fundo e absolutiza a crise da produtividade, pretendendo encontrar sua origem nas relações desarmônicas entre o sistema econômico e a natureza. A ideologia ambientalista, desse modo, veio conceder nova vida ao mito do esgotamento da natureza (BERNARDO, 1979, p. 167).

O fundamento do mito do esgotamento da natureza reside no modelo dos rendimentos decrescentes. Este modelo é caracterizado por uma relação em que um dos elementos se desenvolve permanentemente, enquanto o outro permanece fixo. Assim, os rendimentos obtidos pelo elemento em desenvolvimento serão progressivamente decrescentes, até que o elemento fixo dará a palavra final, impondo o fim do crescimento. As vicissitudes desse modelo na história da teoria econômica são numerosas e expressivas; Bernardo cita o clássico exemplo da teoria populacional de Thomas Malthus, que se mostrou falsa pelos significativos avanços nas técnicas de cultivo. $O$ autor salienta então que o modelo dos rendimentos decrescentes tem servido sobretudo para justificar os critérios capitalistas de produção. Para época nenhuma o modelo dos rendimentos decrescentes pode ter validade, a não ser em análises de curto prazo. Efetivamente, num lapso de tempo demasiadamente curto para a introdução de inovações tecnológicas no processo de fabrico, esse processo constitui um elemento fixo. Mas as pressões da procura que incidem sobre ele levam a reorganizações que, em longo prazo, forçam o desenvolvimento dos elementos do sistema econômico. O modelo dos rendimentos decrescentes, enfim, concebe a atividade econômica somente enquanto dispêndio de produtos e forças produtivas da natureza, sem se dar conta de que por esse mesmo processo são criadas novas capacidades produtivas (BERNARDO, 1979, p. 170-171). 
Em primeiro lugar, esse mito aponta o caráter não-renovável de determinados recursos minerais, sublinhando que seu ciclo de renovação se processa numa escala temporal muitíssimo superior ao das sociedades humanas. Em segundo lugar, Bernardo chama a atenção para o conhecido fato de que as sucessivas previsões apocalípticas dos ambientalistas virem se revelando falsas ou exageradas. O conhecimento de que dispomos sobre as reservas de recursos naturais decorre de pesquisas efetuadas e é impossível defini-las de antemão; no momento em que uma certa matéria-prima começa a escassear, tornando mais difícil e dispendiosa a sua obtenção, seu preço se eleva, e por menor que seja essa elevação ela já será um estímulo para a realização de novas pesquisas, com a conseqüente descoberta de novas jazidas. Por outro lado, a evolução tecnológica nos traz novos processos que substituem os antigos, aumentando a produtividade das matérias-primas ou dando azo a que outras até então consideradas sem serventia entrem na categoria dos recursos importantes, ou mesmo criando substitutos artificiais dos recursos naturais, com a conseqüente multiplicação da produtividade natural. Tais equilíbrios são possibilitados pelo próprio mecanismo capitalista de preços e custos, invalidando grande parte das estimativas dos ambientalistas, até mesmo suas previsões em curto prazo. Em seus modelos as inovações tecnológicas não são inseridas enquanto variável (BERNARDO, 1979, p. 168169). "Torna-se assim um exercício infantil provar que dentro de cem anos, ou cinqüenta, ou vinte, ou mesmo amanhã, os recursos se esgotarão, a poluição envenenará o planeta e esta versão modernizada do juízo final punirá enfim o homem por ter querido dominar as estrelas" (BERNARDO, 1979, p. 169). Mas seria igualmente fácil escolher ao acaso algum momento da história da humanidade e demonstrar que as poluições de então e o esgotamento dos recursos conduziriam rapidamente à catástrofe, caso não tivessem sido introduzidas inovações tecnológicas. Elas surgem justamente por conta da pressão provocada pela ruptura de equilíbrio, estabelecendo um novo equilíbrio até que, no momento de uma nova ruptura e outras inovações, outro equilíbrio se defina, e assim sucessivamente. "As profecias ecológicas relativas à taxa de poluição e ao ritmo de esgotamento dos recursos são, por isso, exercícios de pouco interesse, que revelam tanta 
maestria na preparação de programas para computador como superficialidade na análise dos sistemas econômicos" (BERNARDO, 1979, p. 169).

Este modelo ressurge hoje como expressão de uma reação imediata da ala ambientalista perante a queda na taxa de produtividade. É preciso não só produzir de maneira diferente, mas sobretudo produzir menos. Ou, mais precisamente, a necessidade imediata de produzir menos determinará a maneira futura de reorganizar a produção (BERNARDO, 1979, p. 171).

E por que produzir menos e trabalhar menos? Talvez a seguinte citação responda:

Em conseqüência do colapso financeiro de 2008, a redução das horas de trabalho se espalhou pelos setores privados, públicos e sem fins lucrativos. Os empregadores tentaram evitar lay-offs instituindo amplas reduções nos horários, licenças e outras medidas de redução do trabalho. Esta ética de compartilhamento de trabalho não era amplamente vista nos Estados Unidos desde a década de 1930. Desde que a recessão começou, as horas semanais de trabalho caíram em quase uma hora (WORLDWATCH INSTITUTE, 2010, p. 95).

Durante a extraordinária fase de crescimento da produção consecutiva à reorganização do capitalismo ocidental no pós-guerra, o número dos chamados trabalhadores não-produtivos (administradores, cientistas, burocratas e outros não diretamente envolvidos na fabricação de produtos) alcançou enormes proporções nos países industrializados. Todavia, essa situação idílica não perduraria por muito tempo. Dada a profundidade da crise atual, com a queda nos investimentos e a forte diminuição na utilização da capacidade produtiva instalada, o desemprego crônico e em massa deixou de ser um privilégio dos operários e alastrou-se também entre os trabalhadores qualificados e altamente qualificados. Pela primeira vez na história do capitalismo a classe dos trabalhadores qualificados e grupos sociais afins é atingida por um desemprego de dimensões internacionalmente preocupantes. "Sobretudo, são jovens saídos do ensino superior que não encontram vagas nas profissões gestoriais para que se haviam preparado, e numerosos são portanto aqueles que, no ensino médio ou nas universidades, prosseguem os estudos sabendo de antemão que o desemprego os espera no final". Esses pré-gestores formados e educados para o exercício de funções 
outrora bem determinadas, mas que caem no desemprego antes mesmo de terem qualquer oportunidade de contato direto com a profissão escolhida, limitam-se a encarar o sistema econômico enquanto consumidores. Porém, porque desempregados, são em essência consumidores frustrados. Este conjunto de características dá a essa camada social tão singular funções polivalentes e faz dela o principal elemento aglutinador de classes e grupos sociais distintos, sendo o movimento ambientalista seu novo campo de união (BERNARDO, 1979, p. 178).

Em sendo consumidores, suas reivindicações não vão muito além das reivindicações típicas de consumidores, como a conservação da limpeza das praias para seu bom usufruto nos finais de semana. Mas, em sendo consumidores frustrados, projetam sua situação não como um estado de desfavorecimento social que se deve melhorar ou ultrapassar, e sim como um modelo a ser expandido à generalidade da população. Seja pela sua classe de origem, pela educação recebida, pelo meio em que vivem ou pelas relações sociais estabelecidas, estes elementos concebem-se como parte integrante da classe dominante, recusando-se a partilhar com os excluídos uma mesma mentalidade, mesma luta e mesma visão de mundo. Justamente por se considerarem uma elite, esta classe pretende estabelecer como padrão e norma social a sua atual situação de consumidores frustrados. Tal situação não é encarada por eles como um fator de revolta que os leve a combater o sistema capitalista, lutando contra sua posição desfavorecida no sistema. Ao contrário, eles projetam ideologicamente sua situação de miséria, enaltecendo-a e apresentando-a como o ideal de modo de vida das verdadeiras elites. Ao enaltecerem a situação que ocupam no sistema econômico atual, esses elementos contribuem para sua preservação e reprodução. Apresentam-se dentro do capitalismo com a roupagem de uma nova elite, e sua frustração de consumo transforma-se em apologia da redução de consumo. É por isso que tentam incutir nos movimentos reivindicativos dos consumidores um novo sentido, transformando as pressões sobre a qualidade e o tipo de produtos em propaganda da restrição ao consumo particular, para que a sua redução do nível de vida deixe de ser percebida por eles como 
uma situação de crise e se estabeleça e seja aceita como situação definitiva (BERNARDO, 1979, p. 179-180).

\begin{abstract}
São estes elementos os principais propagandistas da ecologia no que ela tem de mais aberta e ferozmente restritiva do nível de vida estabelecido. Pela situação de consumidores frustrados, são estes os autores e divulgadores dos mais grosseiros mitos contemporâneos, idealizações utópicas das terríveis condições de vida nos modos de exploração arcaicos. Apologistas da situação retardatária e de dependência em que se vive - e sobretudo se morre - nos países exportadores de matérias-primas, pretendem não só mantê-la, mas alargá-la ao proletariado dos países industrializados. A ideologia ecológica chega, com esses elementos, ao seu extremo mais declaradamente imperialista e retrógrado (BERNARDO, 1979, p. 180).
\end{abstract}

O fato é que nos defrontamos aqui com uma contradição interna desse sistema de produção e controle: ele não pode evitar o aumento das expectativas, mas jamais consegue satisfazê-las. "E é justamente nesses momentos de colapso que soluções quixotescas e substitutivos são propostos com tanta paixão ‘humanitária”" (MÉSZÁROS, 2009 , p. 60). Antes dos momentos de crise, ninguém em sã consciência ousaria questionar a sábia superioridade da "eficiência de custos", do "espírito empresarial", da "eficiência tecnológica", das "razões econômicas" e assim por diante. Contudo, basta se tornar clara a impossibilidade da satisfação das expectativas proporcionadas pelo capitalismo, do fornecimento de bens e confortos que ele antes apregoava ruidosamente - enfim, basta ruir a sua auto-intitulada superioridade sobre todos os modos alternativos possíveis de produção e de controle social - que seus apologistas deslocam imediatamente o discurso do louvor às virtudes do consumismo para o louvor à renúncia e à simplicidade, impassíveis não somente quanto à brusca mudança de rumos e à grave incoerência cometida, mas também em relação ao idealismo retórico das "soluções" propostas (MÉSZÁROS, 2009, p. 60). Se esses consumidores frustrados deixam o carro em casa uma vez por semana ou dão carona para um colega de trabalho, não pretendem com isso economizar no combustível; se fazem xixi durante o banho ou se fecham a torneira enquanto escovam os dentes, não pretendem com isso reduzir a conta de água; se reduzem o tempo gasto no chuveiro ou apagam as luzes de cômodos desocupados, 


\section{ANAP

não pretendem com isso economizar na conta de luz; se reciclam ou inventam novos usos para toda sorte de material antes considerado lixo, não pretendem com isso economizar no supermercado; enfim, se eliminam os esbanjamentos e se sujeitam a alguns desconfortos, não é porque reconhecem sua situação de decadência e a necessidade de cortar gastos supérfluos e não-supérfluos: fazem isso em virtude da nobreza de seu caráter, de seu altruísmo, pois reconhecem - diferentemente dos seus invejados esbanjadores, que podem consumir à exaustão - a imperiosa necessidade de salvar o planeta da ameaça galopante do aquecimento global.

Em toda a literatura ambientalista, esta é a condição básica que fundamenta explicitamente a reorganização das condições gerais da produção: a necessidade de uma forte redução e, então, a estagnação do consumo particular. É nesse sentido, em maior ou menor grau, que apontam todas as ideologias ecológicas, da mais séria à mais trapaceira. Para os seus apologistas abriu-se uma nova época econômica, em que o consumo se sacrificaria sistematicamente às necessidades das condições gerais de produção. É neste aspecto que a hipótese do aquecimento global mostra decisivamente a função social que ocupa. Esta corrente aceita como óbvia, irrecusável e imperiosa a contradição entre as condições gerais de produção e o consumo, o que não se trata de uma entidade natural, mas é o resultado das contradições deste sistema econômico. É uma contradição porque os proletários, os verdadeiros produtores dos bens, estão radicalmente apartados da gestão do processo produtivo e da propriedade dos meios de produção. Por isso o interesse da produção desses bens aparece completamente desligado da função última do consumo. O objetivo do capitalista não é fabricar bens de consumo úteis para seus consumidores, nem bens de capital, mas sim apropriar-se da mais-valia produzida pelo proletário, e para tanto pouco lhe importa o caráter material do produto ou seu destino final. Neste tipo de sociedade, os meios de produção e o consumo podem tranqüilamente aparecer como alternativas que excluem uma à outra. Ao aceitarem tal antagonismo como ponto de partida, os ambientalistas inserem-se plenamente no modo capitalista de produção. E, dentre as alternativas postas, não optam pelo lado do consumo, por um consumo mais de acordo com as necessidades e desejos 
do público (o que anuncia sua estratégia repressiva perante o proletariado), e sim optam pela restrição e reestruturação da produção, o que implica de imediato o agravamento das condições de exploração. No projeto ambientalista da sociedade futura, o caráter alienado da exploração capitalista ressalta assim com a maior evidência: é o momento em que o sistema confessa explicitamente, pela boca dos ideólogos que se pretendem seus profetas, que seu objetivo não é sustentar a humanidade, mas sustentar a si próprio, em detrimento dos homens - ou melhor, de certos homens. É o momento em que o capitalismo reconhece que existe unicamente para si próprio. Esta é a mensagem dos ambientalistas (BERNARDO, 1979, p. 172-174).

Acompanhando a tendência de todos os ideólogos das classes exploradoras, os ambientalistas são utópicos nas suas profecias, mas são profundamente realistas nas suas propostas práticas imediatas, que partem do atual declínio das taxas de produtividade e de lucro: reorganização dos investimentos, orientados para a renovação das condições gerais da produção, travagem do progresso técnico aplicado dos bens de consumo e, para preparar uma baixa permanente dos salários, a insistência no cultivo de hábitos frugais, ou seja, a diminuição do padrão de vida socialmente admitido como médio. Estas são as duas facetas indissolúveis das ideologias ambientais: a expansão da produtividade nas condições gerais da produção e restrições ao consumo. Todo o restante não passa de derivações desses aspectos centrais. Esta é a manobra ideológica do Worldwatch Institute e de tantas outras correntes ambientalistas. O ritmo econômico estagnante, as fontes de energia pelas quais têm amor ou ódio, as concepções artísticas e urbanísticas profundamente retrógradas, tudo isso decorre de sua orientação restritiva ao consumo. Enquanto é mantido no plano ideológico, o ritmo de estagnação expresso na proposta do "crescimento zero" não passa de uma utopia. Em sendo um modo de produção de mais-valia, o capitalismo só pode existir em expansão permanente; as crises constituem momentos de ruptura para que o sistema possa se reorganizar e entrar em uma nova fase de reprodução ampliada. Mas enquanto concepção da relação entre as condições gerais da produção e do consumo, o crescimento zero constitui de fato um eloqüente programa. Ele consiste em conservar o consumo particular numa posição 
regressiva, de forma a aumentar assim a mais-valia extorquida e a taxa de lucro, dessa forma acumulando os novos capitais necessários para a grande reorganização das condições gerais da produção (BERNARDO, 1979, p. 176).

Para compreendermos o modo como o programa ambientalista se refletirá nas contradições sociais do capitalismo, precisamos decompor o crescimento nos seus componentes essenciais, pois somente assim poderemos determinar quem lucra com ele e quem arca com seus custos. $O$ equilíbrio estagnante proposto pelo crescimento zero requer uma redução muito considerável no nível médio de vida, que compense a concentração dos investimentos nas condições de produção e a acumulação de capitais a elas destinada. $O$ crescimento zero é o modelo da mais-valia absoluta, em que, dentro de limites constantes, é crescente a mais-valia apropriada pelo capitalista e decrescente o salário do proletário, mas não é só isso. O crescimento zero implica também na manutenção das grandes diferenças existentes entre os níveis de vida dos países industrializados e dos países produtores de matérias-primas, conservando vastas áreas do globo na sua tradicional situação de dependência tecnológica e econômica. $O$ programa ambientalista se mostra assim como a mais extremada manifestação contemporânea do imperialismo. O baixíssimo nível de vida dos países e regiões exportadores de matérias-primas é apresentado como um modelo a ser imposto ao proletariado dos países e regiões industrializados do globo. A elite dos gestores que encabeça as políticas ambientais tece o elogio dos modos de exploração pré-capitalistas, pretendendo reproduzir seus hábitos de vida e seu nível de consumo. "Supremo cinismo, só igualado pelos capitalistas de outrora, quando o escravo era apontado ao proletário como exemplo de obediência, padrão do consumo, modelo de virtudes" (BERNARDO, 1979, p. 177). Eis o verdadeiro sentido do programa ambientalista.

As fontes alternativas de energia constituem um ilustrativo exemplo da insustentabilidade do programa ambientalista. Uma das últimas cenas do documentário The great global warming swindle se passa num pronto-socorro em Nairóbi, cuja eletricidade é garantida por dois painéis solares. Tal energia é suficiente para manter ligada a geladeira (onde se guardam sangue e vacinas) ou a iluminação; se os dois forem 
ligados ao mesmo tempo, o sistema colapsa. As tão idolatradas energias renováveis são sabidamente caras e ineficientes, e ainda assim são as meninas dos olhos dos ambientalistas. Sim, são caras e ineficientes, mas não emitem gases estufa, é isso o que importa. Podemos falar também da energia de biomassa - um saco de gatos que inclui o etanol, bagaço de cana, palha de arroz e lenha (pasmem, lenha é considerado um combustível do futuro...). Não precisamos sequer recorrer às críticas dos céticos; são os próprios ambientalistas que reconhecem que as fontes "alternativas" não são alternativas: "Enquanto o desenvolvimento de fontes de energia renováveis é prioridade, nenhuma alternativa energética atualmente disponível consegue manter as taxas de crescimento econômico global intensivas em recursos de hoje" (WORLDWATCH INSTITUTE, 2010, p. 86). Mas se as fontes alternativas de energia claramente não são uma alternativa, então por que tanta propaganda de suas falsas virtudes? Uma primeira idéia do real motivo do amor dos ambientalistas por essas energias pode estar na seguinte citação:

\begin{abstract}
Seria um tanto desastroso para nós descobrir uma fonte de energia limpa, barata e abundante por causa do que nós faríamos com ela. Devemos procurar por fontes de energia adequadas às nossas necessidades, mas que não nos dêem os excessos de energia concentrada com os quais podemos causar danos à Terra ou aos outros (Amory LOVINS, entrevista à Playboy, nov-dez 1977, citado por DRIESSEN, 2003, p. 93).
\end{abstract}

Ou esta pérola de Paul Ehrlich: "Dar à sociedade energia barata e abundante seria o equivalente a dar uma arma a uma criança idiota" (Paul EHRLICH, An ecologist perspective on nuclear power, 1978, citado por DRIESSEN, 2003, p. 93). O verdadeiro problema da energia para os ambientalistas não parece ser simplesmente a poluição gerada pelas fontes de energia tradicionais. Ao que parece, a queixa também está relacionada ao fato de que os combustíveis fósseis, a hidreletricidade e a energia nuclear cumprem a tarefa para a qual são designados: fornecer energia abundante e confiável. Para os ambientalistas, o mundo em desenvolvimento deve investir majoritariamente em energia solar e eólica e esquecer a hidreletricidade, a energia nuclear e os combustíveis fósseis, o que equivale a privar seus cidadãos de energia abundante e confiável: 


\section{ANAP Brasil}

ISSN 1904-3240

V. 3, n. 3

\section{REVISTA C I E N TÍ F I C A Julho/2010}

[...] se o mundo tiver de evitar mudanças climáticas perigosas, talvez reste pouco espaço na atmosfera para os países pobres se desenvolverem economicamente mediante os mesmos padrões energéticos de uso intensivo de carbono de que os países industrializados dependeram em seu próprio desenvolvimento ao longo dos dois últimos séculos (UNFPA, 2009, p. 1).

Bem entendido: os países pobres, diante da mudança climática, não terão o direito de utilizar as tecnologias baratas e eficientes usadas por sua contraparte desenvolvida, devendo usar as tecnologias caras e ineficientes desenvolvidas pelos países ricos para aprofundar ainda mais o fosso que os separa. Eles devem se conformar com suas terríveis vidas e cultivar seus hábitos frugais tão virtuosos. Isso é condenar bilhões de pessoas à pobreza e à miséria. E tudo isso por nenhuma razão válida, apenas para promover suas ideologias, cuja indiferença a essa pobreza abjeta e à morte prematura provam seu desserviço prestado (DRIESSEN, 2003, p. 93-95).

Mas não é só isso. As empresas dos países ricos precisam vender suas maravilhosas tecnologias de ponta. É por isso que tanto se fala em "parcerias de auxílio ao desenvolvimento sustentável" e em "transferência tecnológica": consistem simplesmente em empurrar para os países pobres as tecnologias caras e ineficientes por elas desenvolvidas, formando assim mais um elo da forte corrente que mantém atada à prosperidade das nações centrais a agonia e a escravidão perpétuas das nações periféricas.

Para além do consumismo e da obsolescência programada, somos subitamente expostos a teorias que defendem a execução de cortes artificiais no fornecimento de energia e a produção artificial de escassez material como antídoto material e ideológico contra a ascensão econômica dos países emergentes, o combate à pobreza e à impossibilidade de ser feliz nesta cultura. Malthus já preconizava a escassez global de recursos e o colapso da humanidade caso uma população crescente tentasse alcançar padrões de vida crescentes; a pobreza material é agora elevada à categoria de virtude e deve ser cultivada e apreciada, pois uma vida simples está mais de acordo com o equilíbrio ambiental do planeta. Você não agüenta mais enfrentar exaustivos 
congestionamentos diários nos trajetos de ida e volta para o trabalho? Experimente ir de bicicleta ou mesmo a pé; além de prestar sua inestimável contribuição contra o aquecimento global e pela melhoria do trânsito caótico de nossas cidades, essa atitude ainda ajuda você a controlar o ponteiro da balança. Sua renda não the permite se alimentar de carne regularmente? Tanto melhor, já que a redução do consumo de carne bovina reduz as emissões de metano para a atmosfera, e esse gás é muito mais poderoso do que o dióxido de carbono para o aquecimento global. De quebra, você desestimula a conversão de alguns hectares da floresta amazônica em pastagens. Seus filhos precisam caminhar dez quilômetros todos os dias para ir à escola? Pois se orgulhe de ter filhos tão conscientes de seu papel de guardiões do clima do planeta e do futuro da humanidade, diferente de seus correspondentes norte-americanos, que terminantemente se recusam a imitá-los. Seus jantares são iluminados a luz de velas? Pois além de contribuir com a redução do consumo de energia elétrica e da demanda pelo alagamento de vastas áreas de florestas virgens, você é um dos poucos felizardos desse mundo que consegue (literalmente) manter acesa a chama do romantismo após tantos anos de casamento. Você não possui uma televisão para assistir ao telejornal e à novela após o jantar? Quem dera houvesse muitos outros como você, que dispõe de bastante tempo para brincar de teatro de sombras com seus filhos, distantes de toda a alienação trazida pelos programas de TV. Sem contar que dormir cedo faz maravilhas pela sua saúde. Você trabalhou duro o ano todo e ainda assim não conseguiu comprar aquele mísero ventilador para aplacar seus dias e noites quentes de verão? Anime-se, pois uma vida simples não só está mais de acordo com o equilíbrio ambiental do planeta, como permite a você desfrutar de sensações mais naturais. Você lava suas roupas no rio, cantando cantigas com suas primas e vizinhas? Pois se reconheça como parte do preciosíssimo patrimônio folclórico do país, tão ameaçado de desaparecer engolido pela cultura de massa. Você precisa tomar banho no rio? Nós da cidade morremos de inveja, pois nosso rio é absolutamente podre. Você cozinha no fogão a lenha? Ah, como a comida é muito mais saborosa quando preparada no fogão a lenha! Ademais, biomassa é um combustível sustentável e reduz a gravidade do aquecimento global. Você precisa plantar seus 
próprios alimentos? É bom saber que ainda existem pessoas que vivem em harmonia com os ciclos naturais e sabem do esforço despendido para levar uma única cenoura à mesa do consumidor urbano, que ignora a origem de seus alimentos. Você nunca na vida usou dinheiro? Está vendo só como ainda é possível viver uma vida menos materialista e mais espiritualizada?! Você faz sacrifícios homéricos para trazer o pão de cada dia para a mesa? Pois então você sabe dar valor às suas conquistas e deve se lembrar sempre que os últimos serão os primeiros. Por onde quer que andemos hoje, somos bombardeados por comandos de uma vida simples, de redução do desperdício e de enaltecimento de uma vida de frugalidade e renúncia. Curiosamente, foram essas as mesmas premissas utilizadas pela Igreja durante a Idade Média: mantinham os servos naquela condição miserável com a justificativa da vontade divina, enquanto clero e senhores feudais se perpetuavam nas melhores condições de vida. $O$ capitalismo pregava exatamente 0 oposto a isto, contudo, o que há poucas décadas seria considerado mais que um delírio do sistema, hoje é enfaticamente recomendado! E todo esse sacrifício na realidade não significa um mal: corresponde ao cumprimento de seu dever de cidadão do mundo, de salvar o planeta!

Através dessa imperceptível artimanha, o sistema capitalista não apenas evita o desafio de enfrentar os fundamentos causais das expectativas frustradas, mas ao mesmo tempo essa própria evasiva passa a ser muito convenientemente justificada, ou melhor, racionalizada (MÉSZÁROS, 2009, p. 60). Ao invés de decretar a absoluta falta de perspectiva do término de sua crise, assumindo assim sua falência, o capitalismo foge ao problema desviando nossas atenções para um problema alegadamente maior, o caos ambiental planetário, e condena toda a humanidade a uma produção artificial de escassez imprescindível para sua reestruturação. Outrora, a dominação era exercida pelo reino do consumo. Hoje, diante do mais absoluto descaso com a solução dos reais problemas humanos (e também dos imaginários!), somos compelidos a acatar a ascensão da dominação legitimada pela virtuosa escassez. A mensagem é: conforme-se com sua vida de pobreza e de decadência, pois não é do escopo deste sistema satisfazer às 


\title{
ANAP
}

suas necessidades e desejos. O único escopo deste sistema é escravizar seus súditos, forçando-os a pagar a conta de sua recuperação:

\begin{abstract}
Da mesma forma, as pessoas deveriam esquecer tudo sobre as cifras astronômicas despendidas em armamentos [e auxílio a bancos falidos!] e aceitar cortes consideráveis em seu padrão de vida, de modo a viabilizar os custos da 'recuperação do meio ambiente': isto é, em palavras simples, os custos necessários à manutenção do atual sistema de expansão da produção de supérfluos. Para não mencionar a vantagem adicional que constitui o fato de se compelir a população em geral a custear, sob o pretexto da 'sobrevivência da espécie humana', a sobrevivência de um sistema socioeconômico que se defronta agora com deficiências derivadas da crescente competição internacional e de uma mudança crescente na sua própria estrutura de produção, em favor dos setores parasitários (MÉSZÁROS, 2009, p. 52).
\end{abstract}

Quando se propõe a adição de um "imposto climático" às tecnologias movidas a combustíveis fósseis, o objetivo não é desestimular o consumo dessa fonte de energia ou por acaso as pessoas deixam de andar de ônibus ou de carro quando sobe o preço da gasolina? Nossa sociedade é movida a combustíveis fósseis e permanecerá nesta estrada ainda por muitas décadas; é inevitável consumi-los em grande escala, não importa quantos impostos sejam criados em nome da salvação do planeta. O objetivo é simplesmente cultivar o saudável e nada frugal hábito de criar novos impostos, sempre com o mesmo objetivo: o equilíbrio das contas públicas de um Estado que gasta muito e mal.

\begin{abstract}
Pode-se assim observar a hipocrisia desavergonhada com que o governo britânico tentou justificar, em 1994, o imposto de valor agregado de $17,5 \%$ sobre o consumo interno de combustíveis - castigando principalmente os pobres e os aposentados de baixa renda - com a desculpa de preocupar-se com o meio ambiente, referindo-se à Conferência do Rio. Na verdade esta medida altamente impopular - que cinicamente transformou no seu contrário a solene promessa eleitoral dos conservadores de reduzir impostos - foi imposta para tentar reduzir um déficit orçamentário anual de $£ 50$ bilhões, sem qualquer expectativa de que o aumento da carga tributária viesse a forçar uma redução do consumo de energia e as conseqüências negativas de se continuar a produzir energia com os mesmos métodos altamente poluidores (MÉSZÁROS, 2002, p. 223, nota de rodapé).
\end{abstract}

Em setembro de 2009, o governo francês também anunciou a criação de uma taxa de $€ 17,00$ sobre a tonelada métrica de dióxido de carbono emitido no consumo de 
combustíveis fósseis. Isso, claro, com o nobre desejo de salvar o planeta do aquecimento global. A taxa carbono representava o carro-chefe da política ambiental do presidente Nicolas Sarkozy, mas não duraria muito. O primeiro-ministro francês, François Fillon, anunciou o fim do imposto climático já em 23 de março de 2010, alegando que ele deveria ser aplicado em nível europeu e "não pesar na competitividade" das empresas francesas. "É preciso dar prioridade ao crescimento, ao emprego, à competitividade, à luta contra os déficits", afirmou o primeiro-ministro, numa memorável demonstração de quanto a preocupação com o futuro do meio ambiente deve estar acima de meras contingências econômicas presentes (CORREIO BRAZILIENSE, 2010). Interessante notar que Sarkozy definiu a taxa carbono como uma "primeira etapa de uma nova revolução industrial", revelando a verdadeira intenção subjacente aos acordos climáticos: a transição da matriz energética, o desenvolvimento de novas tecnologias, a necessidade de reestruturação de um capitalismo em crise.

O culto à frugalidade, ao contrário do que pregam os ambientalistas, não é um movimento de protesto contra a insustentabilidade do sistema capitalista; é antes o atendimento a seus imperativos de reestruturação. Não é através da crítica ao consumo que se pode pôr em xeque a "sociedade de consumo". No capitalismo o consumidor não faz parte do processo produtivo e não pode influenciá-lo decisivamente; a única função da produção e venda de produtos é a realização do lucro, não obedecendo a qualquer critério de utilidade social, e sua comercialização oculta, por detrás da aparência de mercadoria, as verdadeiras relações sociais que lhe embasam. Sendo assim, só se poderá eliminar o consumo de tipo capitalista quando se aniquilar o regime econômico assentado sobre a extração de mais-valia e quando os critérios determinantes da produção forem as necessidades sociais da humanidade. A alienação do consumo não é decorrente da quantidade de bens consumidos, pois o problema não é o que se consome, e sim como se produz. Acreditar na possibilidade de eliminar essa situação de exploração consumindo menos terá como única conseqüência acrescentar à miséria social da alienação a miséria física. Para um autêntico ponto de vista revolucionário, a crítica ao consumo capitalista só faz sentido enquanto um dos aspectos decorrentes da luta central 
contra o processo de exploração, e propor que as pessoas consumam menos sob a alegação de que tal procedimento constitui um feroz ataque às estruturas capitalistas é "tão imbecil e tão reacionário" como impor aos trabalhadores um salário menor sob o argumento de que assim se coloca em xeque o regime de assalariamento (BERNARDO, 1979, p. 180-181). Enfim,

[...] há ainda entre nós 'teóricos' antediluvianos, que esperam enfrentar as dificuldades resultantes da total ausência de sentido de uma existência saturada de commodities, defendendo seriamente a produção de desemprego artificial e miséria, coroando tudo isso com discursos nostálgicos acerca de religiões perdidas e da necessidade de uma novíssima religião artificial (MÉSZÁROS, 2009, p. 61).

É claro que não podemos pressupor que essa imbecilidade de protesto contra a insustentabilidade do sistema na forma da redução forçada do consumo é gratuita; ela possui sua origem. A classe média decadente, como já vimos, em sua posição de gestores potenciais desempregados e consumidores frustrados, faz com que eles sejam os que mais agudamente sintam a necessidade de reorganizar o capitalismo, porém, por se sentirem parte da elite, não se sentem à vontade para se juntar aos movimentos proletários. Por isso seguem a alternativa ambiental, um projeto tecnocrático de reorganização do sistema, e sua situação crítica e desesperadora leva-os a exagerar a doutrina de seus mestres, convertendo-se nos arautos mais barulhentos e mais fanáticos, mas igualmente os mais limitados, e algumas teses que para os teóricos e cientistas ambientais possuem um valor meramente secundário são levadas a pontos extremos por esses elementos, convertendo-se assim em colossais disparates. Por isso o ambientalismo, que entre as camadas intelectuais superiores até consegue conservar um tom sério mínimo e mantém as pretensões à cientificidade, aparece, graças à ação desses benfazejos discípulos, enfeitada com as mais crassas aberrações. "Quanto à sua produção intelectual no movimento ecológico estes elementos são os palhaços" (BERNARDO, 1979, p. 181).

Os consumidores frustrados, no entanto, não desejam permanecer eternamente nesta posição tão humilhante. Eles efetivamente se preocupam com o desemprego 
estrutural e desejam gerar empregos, não para os agricultores de Uganda, é claro, mas para si próprios, empregos que Ihes permitam não exatamente seguir em seu apostolado de salvação do planeta, mas sim dispor de todo o conforto e consumir todos os deslumbrantes e apelativos bens produzidos por tecnologias movidas a combustíveis fósseis. E que melhor ocasião de gerar empregos qualificados do que a hipótese do aquecimento global? Somente no mês de junho de 2010, o Brasil criou sete representações diplomáticas em países-ilhas, a maioria no Pacífico sul, todos unidos com o objetivo de conter a venda de créditos de carbono para algumas atividades que não estão no mercado formal do Protocolo de Kyoto, como a captura e o armazenamento de gás carbônico (FOLHA DE SÃO PAULO, 2010). Será possível calcular todos os empregos diretos e indiretos envolvidos em projetos de armazenamento de carbono em rochas ou no fundo do mar, de inventários de carbono, de reflorestamento e certificação de madeira, de energia eólica e solar, de modelagem climática, de companhias de seguros, de pesquisa e desenvolvimento de biocombustíveis, de indústrias químicas e automobilísticas, de programas de pós-graduação... Que seria de todos eles se a grave ameaça do aquecimento global simplesmente não existisse? Daí a obrigação de "esconder o declínio": criar e manter os empregos de uma massa de burguesia e de classe média decadentes em todo o mundo. É a elas, e não ao planeta, quem devemos salvar.

Eles exprimem assim a falência do sistema capitalista tal como tem funcionado no último meio século, a degradação do mecanismo de expansão do mercado de consumo particular. Os gestores ambientalistas aceitam plenamente a crise atual, em que do declínio da taxa de produtividade resulta a diminuição do ritmo da produção e a restrição do consumo, preparando o terreno para adaptar as condições gerais de produção a uma estagnação duradoura do consumo particular. Eles projetam assim uma forma de capitalismo que cada vez mais terá as condições gerais de produção em si como objetivo fundamental de seu funcionamento (BERNARDO, 1979, p. 171-172). 


\section{ANAP Brasil}

ISSN 1904-3240

V. 3, n. 3

\section{REVISTA C I E N T Í F I C A Julho/2010}

emprego de outros recursos naturais. (...) É curioso observar que o capitalismo, neste estádio do seu declínio, tem de apelar para semelhantes histerias de massas, pretendendo responsabilizar certas formas científicas pelas conseqüências do funcionamento do sistema em geral (BERNARDO, 1979, p. 172).

Os cientistas ambientais ou os membros do WWF e do Greenpeace preocupam-se exclusivamente em desenvolver novas fontes de energia, selecionar as matérias-primas e planejar os passos necessários à transição do sistema atual para aquele que propõem. Seus discípulos ambientalistas passam a vida em elucubrações utópico-místicas e "oferecem como modelo para o sistema de produção na sociedade do futuro a idealização da organização monástica do trabalho prevalecente nos conventos medievais, ou qualquer outra falsificação lírica do passado". Entretanto, nada disso está em sintonia com as necessidades reais da esmagadora maioria de seres humanos. Os ambientalistas são absolutamente silenciosos quanto às relações sociais no processo de produção, à propriedade dos meios de produção, ao controle da gestão e à orientação das decisões (BERNARDO, 1979, p. 184).

Houve um tempo em que a superação da escassez era compatível com os processos e aspirações capitalistas. Hoje em dia, porém, este objetivo aparece somente "nas racionalizações ideológicas dos mais cínicos apologistas do sistema estabelecido". Só isto já nos diz muito sobre o verdadeiro significado e os rumos da reconstrução estrutural capitalista (MÉSZÁROS, 2002, p. 699). Quando o sistema não pode ou não quer eliminar a escassez e a produção do desconforto, transforma-as numa virtude, algo de que deveríamos nos orgulhar! O culto à frugalidade e a produção artificial da escassez, guardiões da natureza, constituem hoje uma autêntica ideologia de legitimação do sistema capitalista: se o capitalismo é o sistema que torna inevitável a produção da escassez e se a escassez é algo desejável e louvável, a conclusão lógica a se tirar é a de que o capitalismo é desejável e louvável. Que ele permaneça conosco para todo o sempre, agora pintado de verde, eterno produtor de escassez eternamente legitimado. 


\section{ANAP

\section{CONCLUSÃO}

Não é a primeira vez na História em que uma cultura de escassez consiste em legitimação do sistema vigente. Esta visão foi implementada durante boa parte da Idade Média, quando o servo era doutrinado a não questionar a sua posição de classe. Deveria servir ao senhor feudal, cultivar, colher, moer, produzir muito, mas consumir quase nada daquilo que produzia. Do pouco que sobrava, ainda apareceria a figura da Igreja para tomar aquilo como dízimo. O importante, vale ressaltar, é que suas almas estariam salvas para um mundo melhor do que aquele em que vivem atualmente. Conseguimos verificar apenas poucas diferenças entre aquela época e a contemporânea. Na condição de servo, quase nada poderia ser feito, já que sua posição foi elencada por ação divina. Na situação contemporânea, o indivíduo escolhe este tipo de vida, muito bem manipulado pela condição da ideologia posta.

Será interessante ver algum historiador da ciência em meados do século XXII narrando a trajetória das ciências ambientais, sempre estreitamente atrelada às mudanças na base tecnológica e decidindo os destinos de toda a humanidade, poder comparável ao exercido pela Igreja Católica durante a Idade Média. Se for um historiador suficientemente perspicaz, perceberá e alertará a todos para o fato de que não era a ciência quem, em sua imparcialidade e incondicional devoção aos valores científicos e humanos, recomendava enfaticamente as sucessivas mudanças na base tecnológica para salvar o planeta e os homens de uma catástrofe que nunca chegava, mas sim o sistema capitalista que a governava e buscava nela o amparo e a legitimação para seus imperativos de constante renovação. Será uma pena, contudo, que só saibamos disso por intermédio desse historiador perspicaz, e não percebamos a novela que se desenrola neste exato momento bem diante de nossos olhos.

Enfim, o discurso ambientalista é usado como encobrimento científico na promoção de políticas que pouco ou nada tem a ver com ciência. Ele representa a oportunidade de estabelecer metas - criação de impostos, imposição de novos hábitos de consumo, censura científica e justificação política - que jamais seriam atingidas por meios legítimos. 


\section{ANAP Brasil}

ISSN 1904-3240

v. 3, n. 3

REVISTA CIENTÍFICA

Julho / 2010

\section{REFERÊNCIAS}

BERNARDO, João. O inimigo oculto: ensaio sobre a luta de classes - manifesto antiecológico. Porto, Afrontamento, 1979.

CORREIO BRAZILIENSE. Governo francês abandona projeto da taxa carbono. In: http://www.correiobraziliense.com.br/app/noticia182/2010/03/23/mundo,i=181505/GOVER $\mathrm{NO}+\mathrm{FRANCES}+\mathrm{ABANDONA}+\mathrm{PROJETO}+\mathrm{DA}+\mathrm{TAXA}+\mathrm{CARBONO}$.shtml (acesso em $14 \mathrm{de}$ junho de 2010).

DRIESSEN, Paul. Eco-imperialism: Green power, black death. Bellevue, Free Enterprise Press, 2003.

FOLHA DE SÃO PAULO. Brasil faz "embaixadas do clima" em países-ilhas. 19 de junho de 2010. In: http://www1.folha.uol.com.br/ciencia/754103-brasil-faz-embaixadas-doclima-em-paises-ilhas.shtml (acesso em 21 de junho de 2010).

MÉSZÁROS, István. Para além do capital. São Paulo, Boitempo, 2002.

A crise estrutural do capital. São Paulo, Boitempo, 2009.

UNFPA. State of the world population 2009 - facing a changing world: women, population and climate. In: http://www.unfpa.org/swp/2009/en/pdf/EN_SOWP09.pdf (acesso em 20 de novembro de 2009).

WORLDWATCH INSTITUTE. State of the world 2010. Transforming cultures: from consumerism to sustainability. In: http://www.worldwatch.org/node/6369 (acesso em 2 de junho de 2010). 